\title{
Anomalous results using countercurrent immunoelectrophoresis for the detection of pneumococcal antigen in Bactec blood culture media
}

\author{
WENDY CHAN CHIANG, GS TILLOTSON, MAEVE GL KEANEY, LEELA A GANGULI \\ From the Department of Microbiology, Hope Hospital, University of Manchester School of Medicine, Salford \\ M6 $8 H D$
}

SUMMARY On examination of Bactec blood cultures for pneumococcal antigen by countercurrent immunoelectrophoresis the consistent presence of a non-specific protein band caused problems with the interpretation of results, even in laboratories experienced in performing countercurrent immunoelectrophoresis. When the Bactec blood culture system is used, countercurrent immunoelectrophoresis should not be relied on for the detection of pneumococcal antigen.

Many rapid techniques for the detection of bacteria in blood have been reported and are valuable aids in the selection of appropriate treatment for bacteraemic patients. The use of countercurrent immunoelectrophoresis has been advocated to detect the soluble capsular polysaccharide antigen of Streptococcus pneumoniae in blood culture specimens. ${ }^{\prime 2}$ Recently, we introduced the radiometric Bactec system into our laboratory and have encountered problems in the interpretation of countercurrent immunoelectrophoresis results using Bactec blood cultures from patients in whom pneumococcal sepsis was suspected clinically. Protein deposits around the anodal well were seen constantly, thus making interpretation difficult. This has not been previously reported.

\section{Methods}

Fischer $e t a l^{3}$ have reported the inability of certain strains of Str pneumoniae to survive in Bactec media. In three patients in whom pneumococcal sepsis was suspected we failed to isolate Str pneumoniae on repeated subculture despite evidence of bacterial growth in our Bactec blood cultures. Two of these had visual evidence of probable bacterial growth-that is, lysis or "chocolatisation" of the blood. The other specimen had an increased growth index and Gram positive diplococci were seen. The normal threshold growth indices used were aerobic 30 and anaerobic 15, and the latter specimen showed increases of 30 to 205 and 3 to 137 for the aerobic and anaerobic bottles respectively. These values refer to a measure of ${ }^{14} \mathrm{C}$ activity with a value of 100 corresponding to approximately $0.025 \mu \mathrm{Ci}$. Pneumococcal antigen was detected by countercurrent immunoelectrophoresis in all three blood cultures by a laboratory experienced in this technique. At that time uninoculated media were not tested by countercurrent immunoelectrophoresis. Further analysis in our own laboratory of uninoculated Bactec media $7 \mathrm{C}$ and $6 \mathrm{~B}$ and simulated pneumococcal blood cultures showed a concave band of non-specific protein deposited near the anodal well. We think this could obscure weak precipitin lines.

Bactec media and other test supernatants were subsequently examined by countercurrent immunoelectrophoresis at four laboratories which were chosen because they were experienced in performing countercurrent immunoelectrophoresis. An identical batch of 11 samples was examined blindly in each laboratory. All were aware that we had a problem with interpretation and that some samples would contain pneumococcal antigen. Each of the laboratories used slightly different electrophoretic techniques (further information is available on request).

\section{Results}

The results obtained are shown in the Table. All noted the thick concave band of non-specific pro- 
Table Results of examination of test supernatants by four laboratories

\begin{tabular}{lllll}
\hline Test supernatants & \multicolumn{4}{l}{ Independent laboratories } \\
\cline { 2 - 5 } & $A$ & $B$ & $C$ & $D$ \\
\hline Nutrient broth & - & - & $(+)^{*}$ & - \\
Brain heart infusion & - & - & - & - \\
Serum alone & - & - & - & - \\
Bactec 6B & - & - & $(+)$ & - \\
Bactec 6B + blood & -+ & - & $(+)$ & $-\neq$ \\
Bactec 6B + antigen & WK+ & - & $(+)$ & + \\
Bactec 6B + blood + antigen & + & - & $(+)$ & + \\
Bactec 7C & - & - & $(+)$ & - \\
Bactec 7C + blood & - & - & $(+)$ & - \\
Bactec 7C + antigen & WK+ & - & $(+)$ & + \\
Bactec 7C + blood + antigen & + & + & + & + \\
\hline
\end{tabular}

*Strong precipitin lines noted but would not report as being pneumococcal.

Probably negative, although non-specific protein band may have obscured a weak precipitin line.

$¥ A$ weak protein precipitate-uncertain result. WK $=$ weak

tein, which was consistently present in all the Bactec media and could not be washed out. Laboratories $A$ and $C$ stated that it could have obscured any weak precipitin lines.

Laboratories $\mathrm{A}$ and $\mathrm{D}$ detected all the expected positive specimens but laboratory A considered that two of the positive reactions were weak and stated that the non-specific protein band could lead to problems of interpretation, particularly in inexperienced hands. Laboratories $\mathrm{B}$ and $\mathrm{C}$ failed to detect antigen in three of the four positive specimens. One of these laboratories $(\mathrm{C})$ stated that strong precipitin lines, not considered to be pneumococcal in origin, were seen in eight specimens (three of which should have been antigen positive). Laboratory $\mathrm{C}$ alone reported a non-pneumococcal precipitin line in an uninoculated nutrient broth; this result remains unexplained.

\section{Discussion}

We believe that the use of countercurrent immunoelectrophoresis for the detection of pneumococcal antigen in blood cultures collected using the Bactec system should not be relied on, as even experienced laboratories encounter problems in the interpretation of results owing to non-specific protein deposits. The latex agglutination system Slidex pneumo-kit (bioMerieux, Lab Impex) seems to be a promising method for the detection of pneumococcal antigen ${ }^{2}$ and our initial investigations suggest that it should be used for the confirmation of pneumococcal bacteraemia when used with Bactec media.

We are grateful to the laboratories for their collective assistance.

\section{References}

' Thompson WE, Wise R. Detection of Streptococcus pneumoniae in blood culture specimens using counter immunoelectrophoresis. Eur J Clin Microbiol 1982;1:123-4.

${ }^{2}$ Thompson WE, Wise R. Comparison of counter immunoelectrophoresis and latex particle agglutination in the detection of Streptococcus pneumoniae in blood cultures. J Hosp Inf 1983;4:165-71.

${ }^{3}$ Fischer GW, Longfield R, Hemming VG, Valdes-Dapena A, Smith LP. Pneumococcal sepsis with false negative blood cultures. Am J Clin Pathol 1982;78:348-50.

Requests for reprints to: Dr L A Ganguli, Microbiology Department, Hope Hospital, Eccles Old Road, Salford M6 8HD, England. 